to the late early Miocene ( 18.2 Ma) (Figs. 1 and 2; Sangiorgi et al., 2008a; 2008c).

The hiatus is marked by a sharp change in sediment color, a few meters above the last abundant occurrence of the middle Eocene marker dinocyst species Phthanoperidinium clithridium. Sediments above the hiatus contain a new dinocyst genus, Arcticacysta, likely of Miocene (Burdigalian) age (Sangiorgi et al., 2008c). The two species found, Arcticacysta backmanii and $A$. moraniae, co-occur and dominate the interval, where sparse reworked dinocysts of Cretaceous to Oligocene age are also found (Fig. 2). Palynological analyses suggest that the hiatus marks the transition from an anoxic environment with a fresh-brackish water lid, to an estuary-like environment, where high freshwater in- put co-occurred with oxygenated bottom waters. When the sediments become palynologically barren (Fig. 2; Sangiorgi et al., 2008a), a fully ventilated oxic marine environment develops, likely as result of the opening and the deepening of the Fram Strait (Jakobsson et al., 2007). High abundance of fern and fungal spores in the sediments around the hiatus indicate that sediment deposition occurred either close to shore or on land, suggesting that unexpectedly, the Lomonosov Ridge remained at or near sea level for the duration of the gap, likely as a consequence of tectonic activity (O'Regan et al., 2008).

\section{Acknowledgements}

We thank the Netherlands Organisation for Scientific Research (NWO) for funding, and the In- tegrated Ocean Drilling Program for providing samples and data. Stefan Schouten, Jaap Sinninghe Damsté, ACEX co-chiefs Jan Backman and Kate Moran, and all the ACEX colleagues are thanked for the fruitful collaboration.

\section{References}

Backman J. et al., 2008: Age Model and Core-Seismic Integration for the Cenozoic ACEX Sediments from the Lomonosov Ridge, Paleoceanography, 23: PA1S03, doi:10.1029/2007PA001476

Brinkhuis, H. et al., 2006: Episodic fresh surface water in the Eocene Arctic Ocean, Nature, 441: 606-609.

Sangiorgi, F. et al., 2008a: A 26 million year gap in the central Arctic record at the Greenhouse-Icehouse transition: Looking for clues, Paleoceanography, 23: PA1S04, doi:10.1029/2007PA001477

Sangiorgi, F. et al., 2008b: Cyclicity in the middle Eocene central Arctic Ocean sediment record: orbital forcing and environmental response, Paleoceanography, 23: PA1508, doi:10.1029/2007PA001487

Sluijs A. et al., 2006: Subtropical Arctic Ocean temperatures during the Paleocene/Eocene thermal maximum, Nature, 441: 610-613.

\title{
Potential imprint of changes in multidecadal climate variability on temperature reconstructions of the past millennium
}

\author{
Michael Schulz and Matthias Prange \\ MARUM - Center for Marine Environmental Sciences and Faculty of Geosciences, University of Bremen, Germany; mschulz@uni-bremen.de
}

\section{Model results suggest that the wider spread of individual Northern Hemisphere temperature reconstructions during cold phases of the last millennium may partly reflect enhanced climate variability at multidecadal timescales.}

A wide range of reconstruction techniques and proxy data have been used to infer how mean temperature of the Northern Hemisphere has changed over the past millennium (Jansen et al., 2007). This research is driven by the important question of whether the rate and amplitude of the warming during the past decades is unprecedented in the framework of the last millennium, that is, before humans affected the Earth System at an unparalleled magnitude.

The individual reconstructions (Jansen et al., 2007; Fig. 6.10 therein) agree with respect to the overall evolution of Northern Hemisphere temperature. This evolution comprises a warming towards the Medieval Warm Period (centered on the $11^{\text {th }}$ century $\left.A D\right)$, a subsequent cooling culminating in the Little Ice Age $\left(16^{\text {th }}\right.$ to mid-19 $9^{\text {th }}$ century $A D$ ), followed by the most recent warming. The reconstructed centennial-scale variability is thought to be mainly driven by changes in total solar irradiance and possibly also by volcanic eruptions (Jansen et al., 2007 and references therein). Upon closer visual inspection, the temperature reconstructions reveal that the widest spread between the reconstructions occurs before and after the Medieval Warm Period (Jansen et al., 2007; Fig. 6.10 therein). That is, the overlap between the individual reconstructions seems to be better for warm than for cold intervals.

Although each reconstruction is based on a proxy calibration in the recent warm

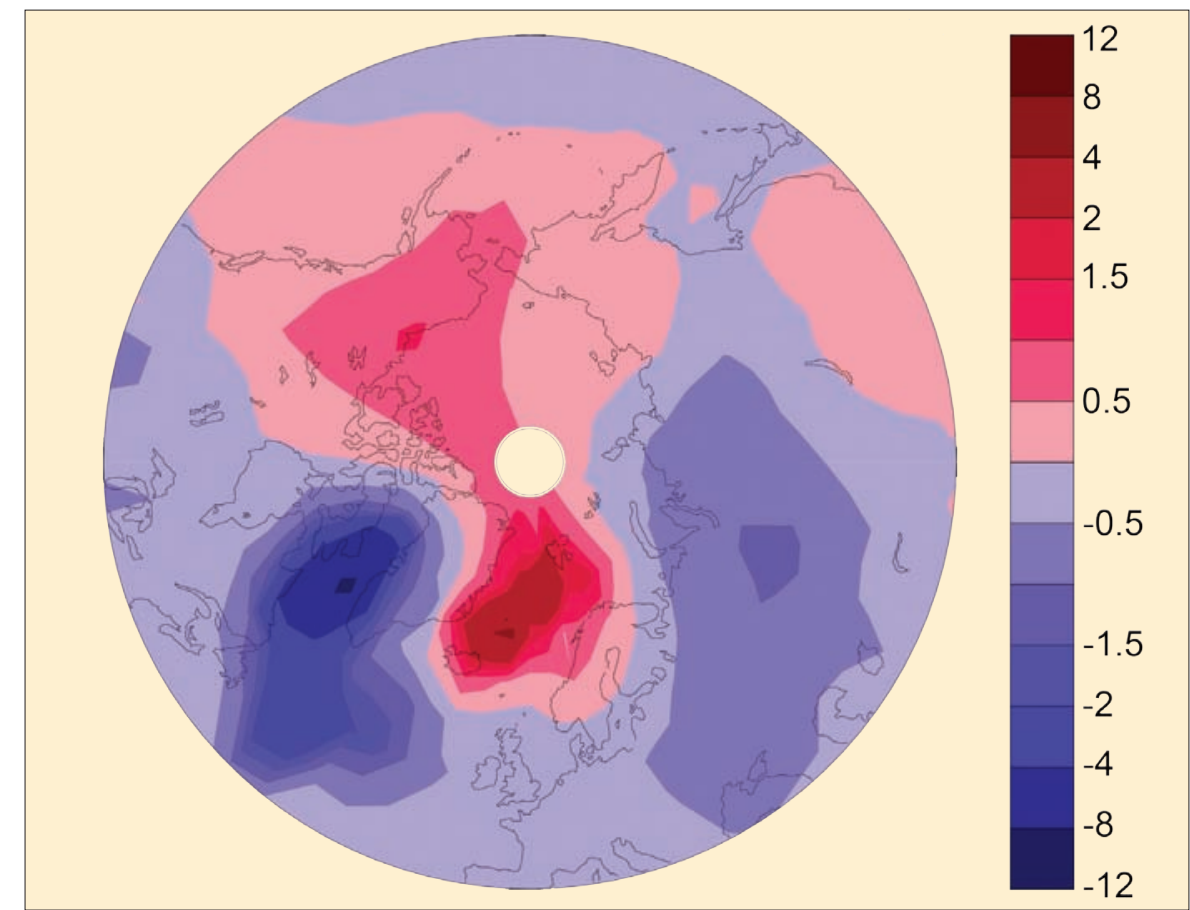

Figure 1: Surface air-temperature difference $\left({ }^{\circ} \mathrm{C}\right)$ between cold and warm mode in the Northern Hemisphere.

period, it appears that the divergence between the individual reconstructions cannot be entirely explained by such a calibration bias (cf., Mann et al., 2008). Another reason for the difference between the reconstructions could be changes in the density of the underlying proxy network, 


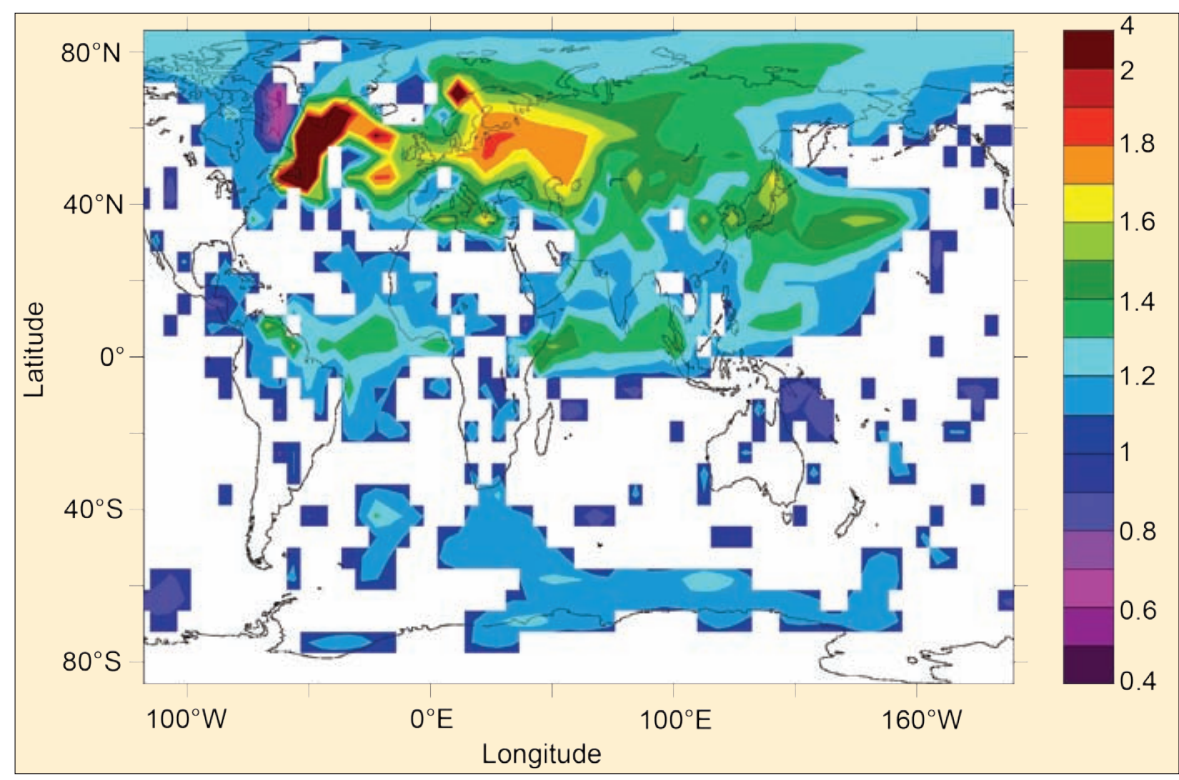

Figure 2: Ratio between surface-temperature standard deviation during the cold and warm modes, respectively. Values larger than unity indicate enhanced temperature variability at multidecadal timescales in the cold mode. Ratios are only depicted if they differ significantly $(a=0.01)$ from unity, taking the autocorrelation of the time series into account.

which is relatively sparse prior to $1400 \mathrm{AD}$. However, as the number of proxy records increases with time, changes in the density of the network alone cannot explain the reduced spread of the reconstructions seen during the transition from the warm $11^{\text {th }}$ into the somewhat colder $12-13^{\text {th }}$ century AD. Here we put forward the idea that the larger spread between the reconstructions during colder phases results from sparse sampling of a temperature field with higher temporal variability.

Model results using a 3D Earth System model of intermediate complexity suggest that the meridional overturning circulation of the Atlantic Ocean can exhibit self-sustained oscillations at centennial to millennial timescales for modern boundary conditions (see Schulz et al., 2007 for further details). The oscillations are characterized by phases of active and inactive deepwater formation in the Labrador Sea. In contrast, deepwater formation in the Nordic Seas is active during all phases of the oscillations. The cessation of deepwater formation in the Labrador Sea during one part of an oscillation excites anomalies in surface temperature that amount to several degrees Celsius over large parts of the Northern Hemisphere at mid-latitudes (Fig. 1). While the principal pattern of these temperature anomalies is rather stable, the actual extent of the anomalies may vary from one oscillation to the next. Due to the overall cooling in the eastern sector of North America as well as over most of Europe we will refer to this phase of the oscillation (i.e., without deepwater formation in the Labrador Sea) as the "cold" mode. The corresponding interval with active deepwater formation will be referred to as the "warm" mode. We argued earlier (Jongma al., 2007) that these types of oscillations for weak solar-irradian tennial to millennial timescales.

To assess the temperature changes further, we analyzed separately the variance of the annual mean surface temperature field within the warm and cold phases of the oscillations. For this purpose, we created two composite time series for the warm and cold mode at each model grid point. The variability in the model at century and longer timescales is associated with the transitions between warm and cold mode. Hence, the composite time series capture only variability at interannual to multidecadal scales. Since our main interest is in multidecadal climate variability, the composite time series were smoothed with a 20-year wide boxcar filter. Subsequently the variance of surface temperature was estimated at each grid point for the warm and cold mode. The model results indicate that temperature variability increased up to 1.7-fold over large parts of northeastern Europe and central Asia during the cold mode (Fig. 2). Over most of North America and the Southern Hemisphere, the model suggests no significant change in variability between the two modes. Upon closer inspection, the model data reveal that the larger variability during the cold mode downstream of the northern North Atlantic is associated with a larger variability in sea ice cover during the cold mode compared to the warm mode.

The band of increased temperature variability extending from Europe to Asia coincides to a large extent with the area from which a large number of proxy records have been generated to quantify temperature changes over the last mil- lennium (Mann et al., 2008). Accordingly, our model results suggest that part of the disagreement between the individual proxy reconstructions, particularly prior to the $15^{\text {th }}$ century $A D$ may result from a too-sparse sampling of a temperature field that exhibited enhanced variability at multidecadal timescales during this cold phase. In other words, it is conceivable that the variation in overlap between the various temperature reconstructions during the past millennium is not only due to "averaging a small number of noisy local temperature estimates" (Mann et al., 2008) but also to the fact that the noise level covaried with climate.

\section{References:}

Jansen, E. et al., 2007: Palaeoclimate. In: Solomon, S. et al. (Eds.) Climate Change 2007: The Physical Science Basis. Contribution of Working Group I to the Fourth Assessment Report of the Intergovernmental Panel on Climate Change, Cambridge University Press, Cambridge, United Kingdom and New York, NY, USA.

Jongma, J.I., Prange, M., Renssen, H. and Schulz, M., 2007: Amplification of Holocene multicentennial climate forcing by mode transitions in North Atlantic overturning circulation, Geophysical Research Letters, 34: L15706, doi:15710.11029/12007GL030642

Mann, M.E., Zhang, Z., Hughes, M.K., Bradley, R.S., Miller, S.K., Rutherford, S. and Ni, F., 2008: Proxy-based reconstructions of hemispheric and global surface temperature variations over the past two millennia, Proceedings of the National Academy of Sciences, 105:13252-13257.

Schulz, M., Prange, M. and Klocker, A., 2007: Low-frequency oscillations of the Atlantic Ocean meridional overturning circulation in a coupled climate model, Climate of the Past, 3: 97-107. 